\title{
REFLEXÕES SOBRE A EDUCAÇÃ̄O FÍSICA NA EDUCAÇÃO INFANTIL ${ }^{1}$
}

Eliana AYOUB*

As discussões em torno da educação física na educação infantil vêm se intensificando desde a publicação da Lei de Diretrizes e Bases da Educação Nacional (LDB no. 9.394/96). De acordo com a nova LDB (Art.26, $\S 3^{\circ}$.), " $A$ educação fisica, integrada à proposta pedagógica da escola, é componente curricular da Educação Básica, ajustando-se às faixas etárias $e$ às condições da população escolar, sendo facultativa nos cursos noturnos".

Podemos considerar que a sua inserção curricular na esfera da educação infantil significa um avanço para o ensino da educação física (Sousa, Vago, 1997, 125). No entanto, sabemos que a construção de uma educação pública, democrática e de qualidade, da qual a educação física seja parte integrante, não depende exclusivamente de leis, mas também, e fundamentalmente, de políticas e ações governamentais que garantam as condições objetivas para a sua concretização. Nesse sentido, ainda temos muito o quê refletir a respeito do espaço da educação física na educação infantil.

Um dos pontos essenciais dessa reflexão diz respeito à organização geral do currículo das creches e pré-escolas, levando em consideração a indissociabilidade entre educação e cuidado (educar e cuidar) no sentido de se buscar uma superação da dicotomia educação/assistência no trabalho com a criança de zero a seis anos de idade.

Em linhas gerais, observamos que alguns estudos propõem uma organização afinada com os princípios de uma pedagogia voltada para a experiência e para o interesse da criança, na qual compete à professora ${ }^{2}$ "generalista" o desenvolvimento das diversas atividades curriculares. Outros estudos sugerem uma organização mais próxima do modelo escolar e centrada em disciplinas. Nesse caso, juntamente com a professora "generalista", aparece a figura da professora "especialista", com formação em diferentes áreas de conhecimento (como a Educação Física, por exemplo) para ministrar aulas específicas.

Abordando o tema do espaço físico como um dos elementos fundamentais para uma Pedagogia da Educação Infantil, Faria (1999) faz uma crítica a um modelo "escolarizante" de educação infantil. Faria $(1999$, p.76) salienta que a configuração de diferentes tipos de espaço em creches e pré-escolas,

(...) com intencionalidade educativa, possibilita superar qualquer resquício: escolarizante (centrado na professora, alfabetizante, seriado, com matérias/disciplinas, etc); assistencialista (não confundir com o direito de todos à assistência); e também adultocêntrico, higienista, maternal, discriminatório, preconceituoso, reforçando o objetivo principal da educação das crianças de 0 a 6 anos que é o cuidado/educação (sem confundir com assistência/escola).

Pensar o espaço e sua arquitetura parece-me tarefa imprescindível para a educação, tanto no âmbito da educação infantil quanto nos outros níveis de ensino. A organização do espaço configura $o$ ambiente do contexto educativo, influenciando as relações humanas. As pessoas produzem o espaço e sua arquitetura e, ao mesmo tempo, são produzidas pelo espaço e sua arquitetura. Nas palavras da italiana Anna Lia Galardini (citado por Faria, 1999, p.85)

Um espaço e o modo como é organizado resulta sempre das idéias, das opções, dos saberes das pessoas que nele habitam. Portanto, o espaço de um serviço voltado para as crianças traduz a

"Faculdade de Educação da Universidade de Campinas. 
cultura da infância, a imagem da criança, dos adultos que o organizaram; é uma poderosa mensagem do projeto educativo concebido para aquele grupo de crianças.

A crítica a um modelo escolarizante de educação infantil tem sido feita por vários autores e vem acompanhada de uma crítica à organização do currículo em disciplinas.

Segundo Sayão (1999, p.226), no caso da pré-escola no Brasil, a idéia de educação física e de outras disciplinarizações surge, num primeiro momento, muito mais no setor privado do que no público, com a proliferação de "escolinhas infantis" nas décadas de 1970 e 1980, “(...) as quais se utilizaram de elementos como o ballet, jazz, inglês, artes marciais e, mais recentemente, da informática como estratégia de marketing para atrair os pais que podiam pagar por isso"

Preocupadas em aumentar a quantidade de alunos, observamos uma verdadeira corrida das "escolinhas infantis" para garantir o seu espaço no mercado educacional. E nessa corrida, associa-se à bandeira da "educação de qualidade" uma pulverização de "aulas de..." que visam preparar a criança para o ensino fundamental e, não seria exagerado dizer, para o mercado de trabalho.

Para Kuhlmann Júnior. (1999, p.64),

É claro que a educação infantil não pode deixar de lado a preocupação com uma articulação com o ensino fundamental, especialmente para as crianças mais velhas que logo mais estarão na escola e se interessam por aprender a ler, escrever, contar. Isso poderia ser resolvido muito mais facilmente se houvesse clareza quanto ao caráter da educação infantil, se a criança fosse tomada como ponto de partida e não um ensino fundamental pré-existente.

Tomar a "criança como ponto de partida" significa pensar num currículo que contemple diferentes linguagens em suas múltiplas formas de expressão, as quais se manifestam por meio da oralidade, gestualidade, leitura, escrita, musicalidade... "Estas formas de expressão, vividas e percebidas pelo brincar, representam a totalidade do 'ser criança' e precisariam estar garantidas na organizacão curricular da sua educação (...) e não enquadradas em áreas do conhecimento e alocadas em disciplinas" (Sayão, 1999, p.234; grifos meus).
A organização curricular em disciplinas com a presença de "especialistas" na educação infantil é uma discussão extremamente complexa que necessita contemplar, de um lado, as hierarquizações presentes entre os(as) profissionais da educação, as quais geram disputas por espaços político-pedagógicos e, de outro, os riscos de uma abordagem fragmentária de conhecimento que tende a compartimentar a criança.

Sabemos que, tradicionalmente, ao profissional "especialista" atribui-se um status superior na carreira docente. Ao abordar "as diferentes 'ordens' hierárquicas entre nós", Campos (1999, p.134) destaca pelo menos três diferentes corpos hierárquicos profissionais no ensino: a) as(os) professoras(es) "generalistas" (na sua maioria mulheres), formadas(os) no curso Normal secundário ou no curso de Pedagogia - que atuam na pré-escola e nas séries iniciais do ensino fundamental (1a. à 4a. série); b) os(as) professores(as) "especialistas", formados(as) em curso superior - que atuam a partir da 5a. série do ensino fundamental, lecionando disciplinas específicas; e c) educadoras(es) leigas(os), mal pagas(os), sem vínculo empregatício formal (na sua maioria mulheres) - que atuam em creches e programas pré-escolares de baixo custo e muitas vezes em programas educacionais ligados a órgãos de assistência social, a entidades filantrópicas ou comunitárias, "Atendem os filhos da pobreza, aquelas crianças e adolescentes que costumam ser rejeitados pelos sistemas formais de ensino" (Campos, 1999, p.135). Ressalta, ainda, que esses corpos hierárquicos sobreviveram a sucessivas reformas educacionais, "(...) incorporando as transformações sociais no seu perfil - perda de prestígio, origem social diversa, condições de trabalho mais dificeis - mas sem perder seus lugares na estratificação interna da profissão" (Campos, 1999, p.135) e que o modo como serão afetados diante das atuais reformas é algo que terá se ser avaliado.

Podemos identificar que esse intenso processo de hierarquização profissional está relacionado tanto com o nível de formação do(a) professor(a) (leigo, secundário e universitário) quanto com o nível de ensino no qual o(a) professor(a) atua (educação infantil, 1a. à 4a. série do ensino fundamental, 5a. à 8a. série do ensino fundamental e ensino médio). $E$, ainda, entre os(as) professores(as) "especialistas" ocorre também uma forte hierarquização em relação à área de formação: educação física e artes são áreas 
consideradas menos "nobres" e, portanto, são desvalorizadas no rol das disciplinas escolares.

Essas hierarquizações, aliadas à ausência de propostas oficiais para uma formação qualificada dos(as) profissionais que atuam e que pretendem atuar na educação infantil, trazem conseqüências extremamente negativas para 0 desenvolvimento do trabalho educativo em creches e pré-escolas.

Referindo-se à qualidade da formação desses(as) profissionais, Barreto (1995, p.14) alerta que:

Se a formação do professor da educação básica como um todo deixa muito a desejar, no caso da educação infantil que abrange $o$ atendimento às crianças de zero a seis anos em creches e préescolas, exigindo que $o$ profissional cumpra as funções de cuidar e educar, o desafio da qualidade se apresenta como uma dimensão maior, pois é sabido que os mecanismos atuais de formação não contemplam essa dupla função.

Lamentavelmente, o "mito", fortemente enraizado entre nós, de que para ser profissional da educação infantil basta ser mulher, delicada e gostar de criança, é confirmado pelas estatísticas que demonstram a presença majoritária de mulheres atuando nesse nível de ensino e a precariedade da formação profissional. Essa concepção precisa ser urgentemente revista! $O$ reconhecimento de que a infância representa um período precioso da educação do ser humano, requer ações efetivas por parte do governo brasileiro em direção à criação de condições para que a educação infantil, que é um direito de todas as nossas crianças, seja tratada com 0 profissionalismo que merece.

(1999, p.74) afirma que,

Sobre esse assunto, Kishimoto

O imaginário popular e até dos meios oficiais pouco afeitos às reflexões sobre a criança e a educação infantil referendam, ainda, a perspectiva romântica do século passado, de que para atuar com crianças de 0 a 6 anos basta ser 'mocinha, bonita, alegre e que goste de crianças', e a idéia de que não há necessidade de muitas especificações para instalar escolas infantis para os pequenos. Essa parece ser também a forma de pensar que reina entre membros do atual Conselho Nacional de
Educação, refletida nas propostas oficiais que se distanciam de uma formação profissional qualificada.

A educação infantil foi inserida na educação básica, portanto, seus profissionais requerem 0 mesmo tratamento dos outros que nela atuam. É preciso eliminar preconceitos arraigados da tradição brasileira, como o de que o profissional que atua com crianças de 0 a 6 anos não requer preparo acurado equivalente ao de seus pares de outros níveis escolares, o que demonstra $o$ desconhecimento da natureza humana $e$ de sua complexidade, especialmente do potencial de desenvolvimento da faixa etária de 0 a 6 anos.

Pensar em uma política de formação profissional para a educação infantil requer, antes de tudo, a garantia de um processo democrático que permita a ascensão na escolaridade, em todos os níveis, e a valorização dessa formação no patamar de outros cursos. Portanto, é preciso pensar também nos leigos, não expulsar os recursos humanos que atuam no sistema.

A diversidade brasileira requer
propostas que atendam às
especificidades do país. Se o contexto
social requer uma formação mais ágil
para essa faixa etária, uma política de
formação profissional deve estimular o
convivio de propostas diferentes, sem
que a faina da quantidade obscureça a
qualidade dessa formação, sem que a
discriminação anule a identidade do
profissional.

Esses são, certamente, desafios serem enfrentados por todos nós.

No que se refere aos riscos de uma abordagem compartimentada de educação infantil, Sayão (1999, p.224) diz que “(...) algumas vezes, a presença da 'especialista' em determinada disciplina na organização curricular é sinônimo de uma concepção fragmentária do conhecimento" Soma-se a isso possíveis indefinições e conflitos em relação aos papéis de cada professora(or), à organização dos horários das aulas na jornada cotidiana e, conforme abordado anteriormente, às hierarquizações e disputas por espaços de trabalho. 
Mas a presença de professoras(es) "especialistas" para trabalhar com linguagens específicas na educação infantil conduz necessariamente à fragmentação de conhecimento e à hierarquização profissional?

Apesar dos sérios riscos existentes nessa direção, acredito que é possível imaginarmos creches e pré-escolas nas quais profissionais de diferentes áreas de formação trabalhem em parceria na educação e cuidado das crianças. No entanto, devemos estar atentos às características das crianças pequenas, cujos vínculos afetivos com as(os) professoras(es) são de extrema importância e demandam tempo para serem construídos, especialmente com as crianças entre zero e três anos de idade. Nessa perspectiva, mudanças excessivas de professoras(es) e/ou atividades durante a jornada diária podem, de fato, gerar fragmentações e causar desconforto, ansiedade e bloqueios que dificultam as relações educativas.

\section{Entretanto,}

as múltiplas relações que podem ser estabelecidas em ambientes 'educativos nos quais convivem crianças de faixas etárias diversas, juntamente com profissionais de várias áreas, além de pais e membros da comunidade, constituem portas de entrada para a construção do conhecimento que se processa quando se respeita a diversidade social e cultural, a multiplicidade de manifestações da inteligência e a riqueza dos contatos com personagens e situações (Kishimoto, 1999, p.73; grifos meus).

Os argumentos da autora a favor das múltiplas relações possíveis e necessárias para a educação das crianças considerando a participação de profissionais de várias áreas, leva-nos a considerar que a. presença de profissionais "especialistas" no contexto da educação infantil pode constituir-se numa rica possibilidade para o desenvolvimento de trabalhos em parceria nesse nível de ensino.

Reforçando a idéia da possibilidade de construirmos relações de parceria, de confiança, não hierarquizadas, entre diferentes profissionais que atuam na educação infantil, poderíamos pensar não mais em professoras(es) "generalistas" e "especialistas", mas em professoras(es) de educação infantil que, juntas(os), com as suas diversas especificidades de formação e atuação, irão compartilhar seus diferentes saberes docentes para a construção de projetos educativos com as crianças. Nesse sentido, poderíamos pensar também em parceria com as crianças, considerando e valorizando as suas experiências e interesses.

"Não considere os seus alunos 'tolos" é um importante alerta de Snyders (1988, p.218) para nós, professoras(es), que pretendemos respeitar nossos alunos e alunas como parceiros(as) culturais, tenham eles(as) zero ou cem anos de idade. Somos todos, professores(as) e alunos(as), seres humanos inconclusos, em constante processo de constituição. E nessa relação de ensinoaprendizado, mediada pelas(os) professoras(es), são múltiplos os caminhos que construímos para nos tornamos professoras(es).

"Como nos tornamos professoras?" é o nome da brilhante obra de Roseli Fontana (2000), na qual a autora convida-nos a refletir sobre essa inquietante busca que se concretiza cotidianamente no tecer da própria vida.

Tempo, acaso e significação... Drama... Vida...

No tempo, vivemos e somos nossas relações sociais, produzimo-nos em nossa história. Falas, desejos, movimentos, formas perdidas na memória. No tempo nos constituímos, relembramos, repetimo-nos e nos transformamos, capitulamos e resistimos, mediados pelo outro, mediados pelas práticas e significados de nossa cultura. No tempo, vivemos o sofrimento e a desestabilização, as perdas, a alegria e a desilusão. Nesse moto contínuo, nesse jogo inquieto, está em constituição nosso 'ser profissional (Fontana, 2000, p.180).

E esse processo de constituição de nosso "ser profissional" se faz e se refaz a cada dia, a cada jornada, com parcerias, em meio a desafios, conquistas, temores, encontros, desencontros, conflitos, buscas... Pois se somos seres inconclusos, como nos ensina Paulo Freire (1997, p.64), "A consciência do mundo $e$ a consciência de si como ser inacabado necessariamente inscrevem o ser consciente de sua inconclusão num permanente movimento de busca"

Pensando na "criança como ponto de partida" na educação infantil, a expressão corporal 
caracteriza-se como uma das linguagens fundamentais a serem trabalhadas na infância. A riqueza de possibilidades da linguagem corporal revela um universo a ser vivenciado, conhecido, desfrutado, com prazer e alegria. Criança é quase sinônimo de movimento; movimentando-se ela se descobre, descobre o outro, descobre o mundo à sua volta e suas múltiplas linguagens. Criança é quase sinônimo de brincar; brincando ela se descobre, descobre o outro, descobre o mundo à sua volta e suas múltiplas linguagens. Descobrir, descobrir-se. Des-cobrir, tirar a cobertura, mostrar, mostrar-se, decifrar... Alfabetizar-se nas múltiplas linguagens do mundo e da sua cultura.

A contribuição da educação física na educação infantil, “(...) para ser relevante $e$ justificada, precisa auxiliar na leitura do mundo, por parte das crianças com as quais trabalha, partindo do pressuposto da construção de si mesmo, no decorrer desse processo de 'alfabetização"' (Grupo de Estudos Ampliado de Educação Física, '1996, p.51).

A educação física na educação infantil pode configurar-se como um espaço em que a criança brinque com a linguagem corporal, com o corpo, com o movimento, alfabetizando-se nessa linguagem. Brincar com a linguagem corporal significa criar situações nas quais a criança entre em contato com diferentes manifestações da cultura corporal (entendida como as diferentes práticas corporais elaboradas pelos seres humanos ao longo da história, cujos significados foram sendo tecidos nos diversos contextos sócio-culturais ${ }^{3}$ ), sobretudo aquelas relacionadas aos jogos e brincadeiras, às ginásticas, às danças $\mathrm{e}$ às atividades circenses, sempre tendo em vista a dimensão lúdica como elemento essencial para a ação educativa na infância. Ação que se constrói na relação criança/adulto e criança/criança e que não pode prescindir da orientação do(a) professor(a):

(...) deixar a criança brincar como queira, como se jogar fosse algo da natureza biológica da espécie, que não necessita de suportes culturais. Assumese, então, uma 'concepção' espontaneísta de educação que afasta o professor como figura de interação $e$ interlocução, ou seja, como parceiro da criança em seu processo de desenvolvimento, ignorando que neste processo certas noções estão se construindo, ou antes, poderão se construir, desde que se cuide para a ocorrência disto (Oliveira, 1996, p.137).

Favorecer a brincadeira no contexto da educação infantil não pode levar a uma atitude de "laissez faire" - abandono pedagógico, de abrir mão da mediação do adulto no processo educativo com a criança. Ao contrário, é no contexto da brincadeira que precisamos aprender a realizar 0 nosso papel: "(...) o papel do professor como mediador, intencional e explícito, do processo de elaboração dos conceitos sistematizados na relação de ensino" (Fontana, 1996, p.43).

De acordo com o Grupo de Estudos Ampliado de Educação Física (1996, p.64) ${ }^{4}$ :

$\mathrm{Na}$ Educação Física a cultura corporal/de movimento traz no seu campo-objeto de conhecimento, manifestações corporais já presentes na vida das crianças, que deverão ser tematizadas com elas, não só na aula dessa disciplina, como também em outros momentos, atendendo assim, a perspectiva de articulação a ser desenvolvida pela equipe pedagógica (grifos meus).

Sob essa ótica, a linguagem corporal não é uma "propriedade" da educação física e, embora seja a sua especificidade, deve ser trabalhada em outros momentos da jornada educativa, tendo a dimensão lúdica como princípio norteador.

Considerando as especificidades da educação infantil e da educação física, qual o(a) profissional que deveria trabalhar com a educação física nesse nível de ensino?

$$
\text { Constata-se que, “(...) }
$$

tradicionalmente, não há, nos cursos de licenciatura em Educação Física, uma preocupação em formar professoras para intervirem na educação de zero a seis anos" (Sayão, 1999, p.223). Quando essa preocupação existe, na maioria das vezes, a formação fica restrita ao aprendizado de um conjunto de atividades corporais (especialmente jogos e brincadeiras) para serem desenvolvidas com as crianças de acordo com as diferentes faixas etárias. As discussões em torno da educação infantil como um todo, suas problemáticas específicas e suas relações mais amplas com o contexto educacional brasileiro, parecem não fazer parte da formação dos(as) licenciados(as) em educação física. 
Em decorrência disso, podemos observar que quando há professoras(es) de educação física trabalhando em diferentes espaços de educação infantil, acabam atuando, predominantemente, como meros "aplicadores de joguinhos" que têm como função primordial "divertir" as crianças. Somos os "especialistas em brincadeiras" responsáveis pelo corpo, pelo movimento e pela diversão das crianças.

Nesse caso, a presença dos(as) "especialistas" em educação física pode gerar uma concepção compartimentada de criança e acentuar "velhas" dicotomias bastante conhecidas no espaço escolar: a professora de educação física fica responsável pelo "corpo" das crianças e a professora "generalista" pelo "intelecto", como se isso fosse possível. Essa visão dicotômica, relacionada à tradição racionalista ocidental, enfatiza, ainda, a superioridade do "intelecto" sobre o "corpo". Conforme afirma (Bracht, 1999, p.70):

A tradição racionalista ocidental tornou possível falar confortavelmente da possibilidade de uma educação intelectual, por um lado, e de uma educação física ou corporal, por outro, quando não de uma terceira educação, a moral (...). Essas educações teriam alvos bem distintos: o espiritual ou o mental (o intelecto), por um lado, e o corpóreo ou físico, por outro, resultando da soma a educação integral (educação intelectual, moral e física). (...) Também na melhor tradição ocidental, a educação 'corporal' vai pautar-se pela idéia, culturalmente cristalizada, da superioridade da esfera mental ou intelectual - a razão como identificadora da dimensão essencial e definidora do ser humano. O corpo deve servir. O sujeito é sempre razão, ele (o corpo) é sempre objeto; a emancipação é identificada com a racionalidade da qual o corpo estava, por definição, excluído.

Outro aspecto a ser considerado é que, muitas vezes, por existir um espaço específico para um trabalho corporal nas aulas de educação física, nos demais tempos da jornada cotidiana, acentua-se um trabalho de natureza intelectual no qual a dimensão expressiva por meio da gestualidade é praticamente esquecida. A aula de educação física passa, então, a ser vista como a "dona" do corpo e do movimento das crianças. Somando-se a isso o possível caráter lúdico das atividades corporais, é comum vermos crianças sedentas pela aula de educação física quando chegamos às escolas; salta-me aos olhos imagens de "explosão corporal" diante da possibilidade de "libertar-se das carteiras escolares" que funcionam, na maioria das vezes, como "armaduras corporais", até mesmo em pré-escolas.

Se nós, profissionais da educação física, queremos uma educação de qualidade em que haja espaço para

(...) a vivência das múltiplas linguagens
produzidas pela humanidade, não podemos nos submeter a ocupar espaços que se configuram como simples preenchimento de tempo ou como compensação das necessidades de movimento que as crianças são vítimas face a certas concepções de Educação Infantil que se propõem a preparar as crianças para a la. série, forjando um ensino mecânico, repetitivo, alienante e conseqüentemente, disciplinador do corpo (Grupo de Estudos Ampliado de Educação Física (1996, p.49).

Entretanto, não podemos negar que a especificidade da educação física localiza-se justamente no âmbito da cultura corporal. Assumirmos essa especificidade, sem a pretensão de sermos os "donos" da expressão corporal das crianças, pode ser um importante ponto de partida para configurarmos entrelaçamentos com diferentes áreas de conhecimento.

Outra situação a ser refletida diz respeito ao fato de não ser raro encontrarmos préescolas do setor privado com aulas de "balé" para as meninas e de "judô" para os meninos. Nesses casos, além de se limitar as possibilidades das crianças de contato com diferentes temas da cultura corporal, reforça-se uma visão "sexista", extremamente equivocada. As crianças, desde muito cedo, vão aprendendo que "dança é coisa de menina" e "luta é coisa de menino", reforçando esteriótipos em relação às práticas corporais e aos diferentes papéis sociais desempenhados por meninas e meninos, mulheres e homens. Mais tarde, serão o "futebol dos meninos" e o "vôlei das meninas" alguns dos principais exemplos de esteriotipias no âmbito da educação física escolar, as quais têm reforçado a idéia de turmas separadas em meninos e meninas nas aulas de educação física.

Reconhecer as discriminações e os preconceitos vividos nas aulas de educação física a 
partir das relações de gênero pode ser um dos primeiros passos para um entendimento acerca dos processos de construção de esteriotipias. E, "Sendo gênero uma categoria relacional, há de se pensar sua articulação com outras categorias durante as aulas de educação fisica, porque gênero, idade, força e habilidade formam um "emaranhado de exclusões' vividos por meninas e meninos na escola" (Sousa \& Altmann, 1999, p.56).

Pensar numa educação e numa educação física preocupadas com a co-educação de nossas crianças, requer ações que contribuam para uma desmistificação de esteriótipos sexuais.

A desmistificação dos esteriótipos sexuais, mesmo esses tendo sua base na educação familiar e uma história cultural (...), deve, então, passar pela escola e pela Educação Física, pois esta, no contexto escolar, se constitui no campo, onde, por excelência, acentuam-se as diferenças entre homem e mulher. Isso porque (...), a Educação Física tem se desenvolvido como uma 'atividade', em que o movimento é considerado a partir de disponibilidades/possibilidades físicas que os seus executantes oferecem (Saraiva, 1999, p.177).

Nessa perspectiva, a co-educação deve ser um princípio educativo a ser adotado a partir da educação infantil. Assim como Sousa \& Altmann (1999, p.64), acredito “(...) que existe a possibilidade de ampliação de espaços para a construção de relações não-hierarquizadas entre homens e mulheres, para a qual a escola pode contribuir" e, eu diria ainda, para a qual a educação infantil tem um papel imprescindível.

Apesar das deficiências na formação do(a) profissional da educação física para atuar no contexto da educação infantil, as quais têm favorecido posturas e ações equivocadas, a minha vivência como professora de educação física em turmas pré-escolares, aliada às experiências dos(as) alunos(as) das disciplinas "Prática de Ensino e Estágio Supervisionado" da Faculdade de Educação Física da Unicamp ${ }^{5}$, levam-me a crer que a presença do(a) profissional da educação física na educação infantil pode colaborar muito positivamente na educação das crianças, desde que essa presença seja compreendida como uma possibilidade de desenvolvimento de trabalhos em parceria, sem hierarquizações, de "mãos dadas" 6

\section{MÃOS DADAS}

Não serei o poeta de um mundo caduco.

Também não cantarei o mundo futuro.

Estou preso à vida e olho meus companheiros.

Estão taciturnos mas nutrem grandes esperanças.

Entre eles, considero a enorme realidade.

O presente é tão grande, não nos afastemos.

Não nos afastemos muito, vamos de mãos dadas.

(...)

O tempo é a minha matéria, o tempo presente, os homens presentes, a vida presente

(Carlos Drummond de Andrade, 1983, p.108; grifos meus).

De "mãos dadas" temos um longo caminho a construir em busca de centros de educação infantil nos quais o educar e o cuidar estejam sempre presentes nas relações com as crianças; centros de educação infantil nos quais as crianças sejam vistas no tempo presente, como seres humanos em constituição, e não como futuros alunos do ensino fundamental e/ou como futuros adultos no mercado de trabalho; centros de educação infantil nos quais as crianças possam descobri-se, descobrir o outro, descobrir o mundo e suas múltiplas linguagens por meio do brincar; enfim, centros de educação infantil nos quais seja realizado um trabalho efetivamente de parcerias (entre os(as) profissionais, as crianças, os familiares e a comunidade) que contribua para uma educação verdadeiramente humana, na qual haja espaço para o diálogo, para o lúdico, para a vida.

\section{NOTAS}

1. Mesa Redonda "Educação Infantil e a formação de professores".

2. Fiz a opção de utilizar o termo professora no feminino, ao invés da utilização genérica da palavra masculina professor, por considerar que na educação infantil, historicamente, esse papel social vem sendo desempenhado majoritariamente pelas mulheres.

3. A concepção de cultura corporal é aprofundada na obra "Metodologia do ensino de Educação Física", de Soares, Taffarel, Varjal, Castellani Filho, Escobar \& Bracht (1992). 
4. Este grupo foi constituído a partir de uma parceria entre o Núcleo de Estudos Pedagógicos da Educação Física da Universidade Federal de Santa Catarina (NEPEF/UFSC) e a Divisão de Educação Física da Secretaria Municipal de Educação da Prefeitura de Florianópolis/SC (SME de Florianópolis/SC), cujos trabalhos desenvolvidos, ao longo de quatro anos, foram publicados num Caderno de Educação Física intitulado "Diretrizes curriculares para a educação fisica no ensino fundamental e na educação infantil da rede municipal de Florianópolis-SC' (1996).

5. Sou responsável pelas disciplinas "Prática de Ensino de Educação Física e Estágio Supervisionado I e II" do Curso de Licenciatura da Faculdade de Educação Física da Unicamp, desde 1998.

6. Uma experiência nesse sentido foi relatada no artigo "Uma proposta de abordagem do tema JOGO no contexto da Educação Física Escolar" (Ayoub, 1999).

\section{REFERÊNCIAS BIBLIOGRÁFICAS}

ANDRADE, C.D. Antologia poética. 18.ed. Rio de Janeiro, José Olympio, 1983.

AYOUB, E. Uma proposta de abordagem do tema jogo no contexto da educação física escolar. In: CONGRESSO REGIONAL SUDESTE DO COLÉGIO BRASILEIRO DE CIÊNCIAS DO ESPORTE/JORNADA PRÉ-CONBRACE, 1., 1999. Anais. p.39-43.

BARRETO, A.M.R.F. Educação infantil no Brasil: desafios colocados. Caderno CEDES: Grandes políticas para os pequenos: educação infantil, n.37, p.7-21, 1995.

BRACHT, V. A constituição das teorias pedagógicas da educação física. Caderno CEDES: Corpo e Educação, n.48, p.69-88, 1999.

CAMPOS, M.M. A formação de professores para crianças de 0 a 10 anos: modelos em debate. Educação \& Sociedade: formação de profissionais da educação: políticas e tendências, n.68, p.126-142, 1999.

FARIA, A.L.G. O espaço físico como um dos elementos fundamentais para uma pedagogia da educação infantil. In: FARIA, A.L.G., PALHARES, M.S., orgs. Educação infantil pós LDB: rumos e desafios. Campinas, Autores Associados/FE/UNICAMP, 1999. p.67-97.
FARIA, A.L.G.; PALHARES, M.S., orgs. Educação infantil pós LDB: rumos e desafios. Campinas, Autores Associados/FE/UNICAMP, 1999.

FONTANA, R.A.C. Como nos tornamos professoras? Belo Horizonte, Autêntica, 2000.

Mediação pedagógica na sala de aula. 2.ed. Campinas, Autores Associados, 1996.

FREIRE, $P$ Pedagogia da autonomia: saberes necessários à prática educativa. 2:ed. Rio de Janeiro, Paz e Terra, 1997.

GRUPO DE ESTUDOS AMPLIADO DE EDUCAÇÃO FíSICA. Diretrizes curriculares para a educação física no ensino fundamental e na educação infantil da rede municipal de Florianópolis-SC: registro da parceria NEPEF/UFSCSME/Florianópolis, 1993 a 1996. Florianópolis, NEPEF/UFSC-SME, 1996.

KISHIMOTO, T.M. Política de formação profissional para a educação infantil: pedagogia e normal superior. Educação \& Sociedade: formação de profissionais da educação: políticas e tendências, n.68, p.61-79, 1999.

KUHLMANN JUNIOR, M. Educação infantil e currículo. In: FARIA, A.L.G., PALHARES, M.S., orgs. Educaçã่o infantil pós LDB: rumos $\mathrm{e}$ desafios. Campinas, Autores Associados/FE/UNICAMP, 1999. p.51-65.

OLIVEIRA, Z.M.R. A brincadeira e o desenvolvimento infantil: implicações para a educação em creches e pré-escolas. Motrivivência, v.8, n.9, p.136-45, 1996.

SARAIVA, M.C. Co-educação física e esportes: quando a diferença é mito. Ijuí, UNIJUí, 1999.

SAYÃO, D.T. Educação física na educação infantil: riscos, conflitos e controvérsias. Motrivivência, v.11, n.13, p.221-38, 1999.

SNYDERS, G. A alegria na escola. São Paulo, Manole, 1988.

SOARES, C.L.; TAFFAREL, C.N.Z.; VARJAL, E.; CASTELLANI FILHO, L.; ESCOBAR, M.O.; BRACHT, V. Metodologia do ensino de educação física. São Paulo, Cortez, 1992.

SOUSA, E.S.; ALTMANN, H. Meninos e meninas: expectativas corporais e implicações na educação fisica escolar. Caderno CEDES: Corpo e Educação, n.48, p.52-68, 1999.

SOUSA, E.S.; VAGO, T.M. O ensino de educação fisica em face da nova LDB. In: COLÉGIO BRASILEIRO DE CIÊNCIAS DO ESPORTE, org. Educação física escolar frente à LDB e aos PCNs: profissionais analisam renovações, modismos e interesses. Ijuí, Sedigraf, 1997. p.121-41.

ENDEREÇO: Eliana Ayoub

R. Mogi Guaçu, 1441 - Chácara da Barra

013093-000 - Campinas - SP - BRASIL

eayoub@terra.com.br 